\title{
New Realization of Quadrature Oscillator using OTRA
}

\author{
Gurumurthy Komanaplli, Neeta Pandey, Rajeshwari Pandey \\ Departement of Electronics and communication Engineering, Delhi Technological University, India
}

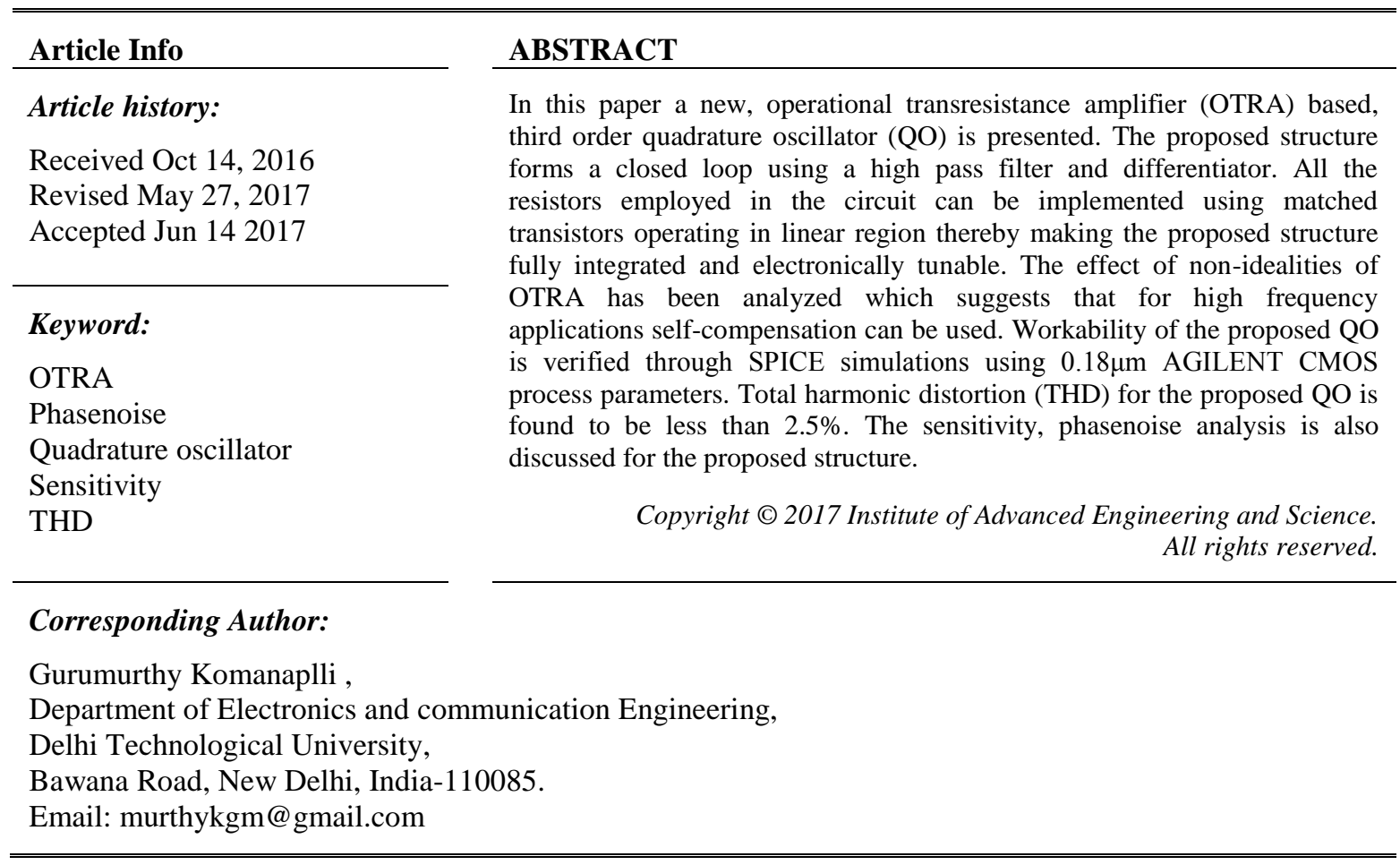

\section{INTRODUCTION}

In last few decades current-mode $(\mathrm{CM})$ processing has evolved as a promising design technique to provide efficient solutions to circuit design problems. This evolution has resulted in emergence of numerous $\mathrm{CM}$ analog building blocks [1].The operational trans resistance amplifier (OTRA) is one among these blocks. It is a high gain current input, voltage output amplifier [2] and uses current feedback technique which makes its bandwidth almost independent of the closed loop gain. Additionally it is free from the effect of parasitic capacitances at the input due to virtually internally grounded input terminals [2] and hence non-ideality problem is less in circuits implemented using OTRA.

Quadrature oscillators (QO) are an important class of circuits and find wide application in communication, power electronics and instrumentation. This has led a consistent research effort towards second order QO design using wide variety of active blocks, as is evident from vast literature available [2-14] .It is well known that higher order networks, provide better accuracy, frequency response and distortion performance [15-17] as compared to lower order circuits. Owing to this in recent past few third order QO designs [15], [16], [18-32] have been reported. Realizing sinusoidal oscillator using closed loop with positive feedback is a well-established method. A careful observation suggests that all the reported third order QO designs are based on forming closed loop using combinations of lossy and/or lossless integrators. In this paper a new OTRA based third order QO is proposed that adapts the scheme of using second order high pass filter and a differentiator in a feedback loop [32].A comparative statement of the proposed structure with previously reported QO circuits is recorded in Table 1. It may be observed from the table that the available topologies-presented in [19] are realized using op-amps however, the constant gain-bandwidth product and lower slew rate of the op-amps limit their high frequency operations. Additionally these circuits use more number of active components as compared to proposed circuit

a. Lack electronic tunability [15], [19], [20], [24]

b. Use mix of active blocks such as DDCC and OTA [28],CCCDTA and OTA [29],CCCCTA and OTA [30] 
c. Provide voltage output at high impedance [15], [16], [20], [22], [24], [25], [28], [29], [31] making a buffer necessary to drive the voltage input circuits

d. Provide current output [18], [20-22]which need to be converted to voltage for circuits requiring voltage inputs and would considerably increase the component count

Table 1. A comparative statement of the proposed structure with previously reported QO circuits

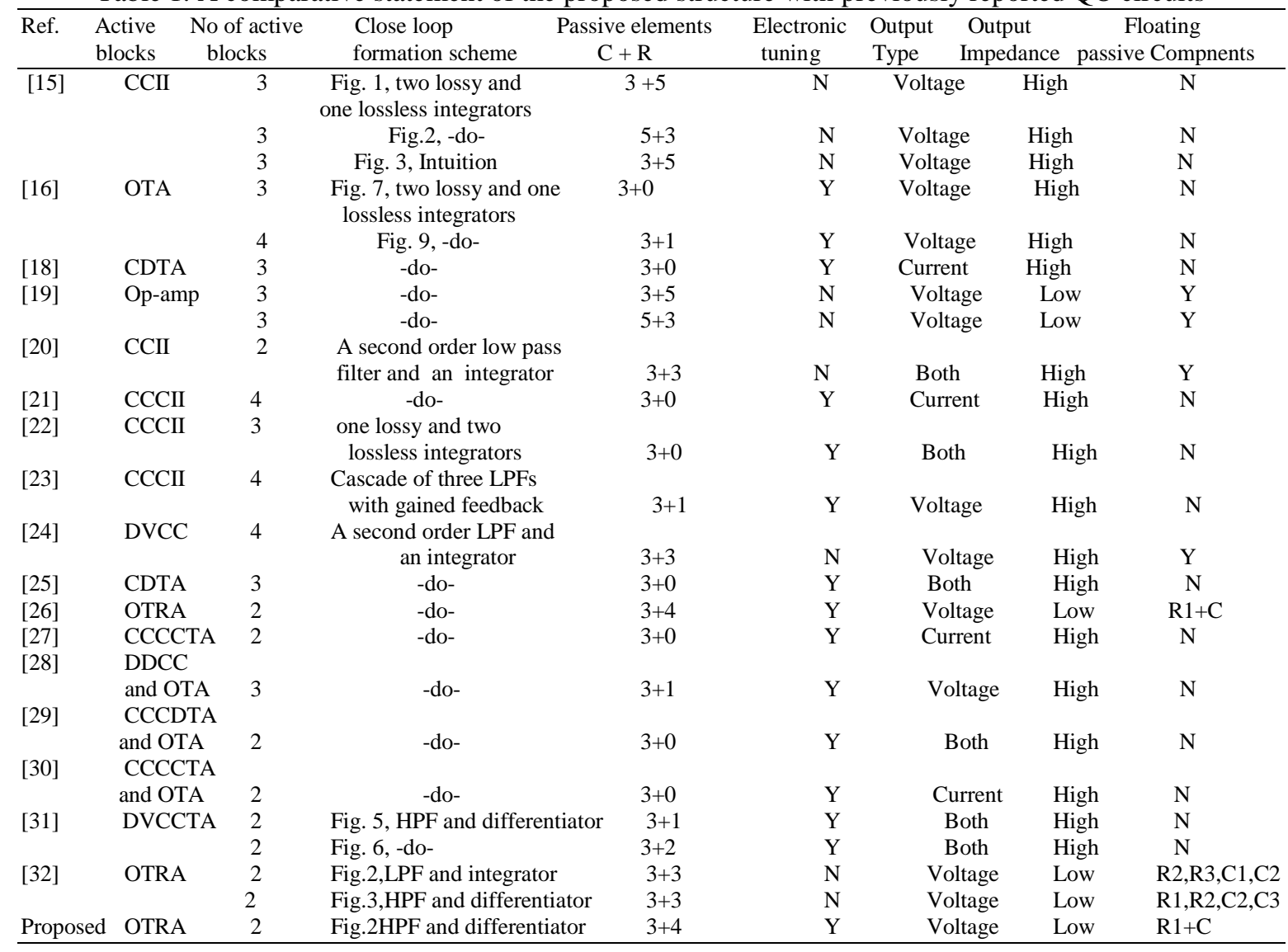

Above discussion suggests that OTRA based QO is most suitable choice for voltage output configurations.Rest of the paper is as organized as follows: in section 2 proposed circuit is described followed by Effect of nonideality of OTRA is dealt in section 3. Section 4 explains the MOS-C implementation details of proposed structure. Proposed structured is verified experietally by contructing OTRA using offshelf IC's AD844 [34], phase noise analysis using the method discussed in [35], [36] is presented in section 5. Sensitivity analysis are discussed in section 6 . The simulation and experimental results are presented in section 7 and paper is concluded in section 8 .

\section{PROPOSED CIRCUIT}

The circuit symbol of OTRA is shown in Figure 1 and its port characteristics are given by

$$
\left[\begin{array}{l}
V_{p} \\
V_{n} \\
V_{0}
\end{array}\right]=\left[\begin{array}{cccc}
0 & 0 & & 0 \\
0 & 0 & & 0 \\
R_{m} & -R_{m} & 0 &
\end{array}\right]\left[\begin{array}{c}
I_{p} \\
I_{n} \\
I_{0}
\end{array}\right]
$$

The output voltage is the difference of two input currents multiplied by trans-resistance gain $\left(\mathrm{R}_{\mathrm{m}}\right)$. Ideally the trans-resistance gain $\mathrm{R}_{\mathrm{m}}$ approaches infinity and therefore the OTRA must be used in a negative feedback configuration [2]. The proposed QO topology is shown in Figure 2. It uses an OTRA based second order high pass filter [32] $\left(\mathrm{C}_{1}=\mathrm{C}_{3}\right)$ and an inverting differentiator in the feedback forming a closed loop, which results in a third order characteristic Equation given by 


$$
s^{3} C_{1} C_{3} R_{D} C_{D}+s^{2} C_{1} C_{2}+s\left(\frac{C_{1}}{R_{2}}+\frac{C_{2}}{R_{1}}\right)+\frac{1}{R_{1} R_{2}}=0
$$

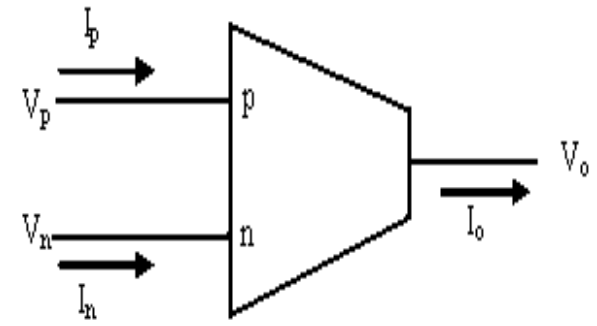

Figure 1. OTRA circuit

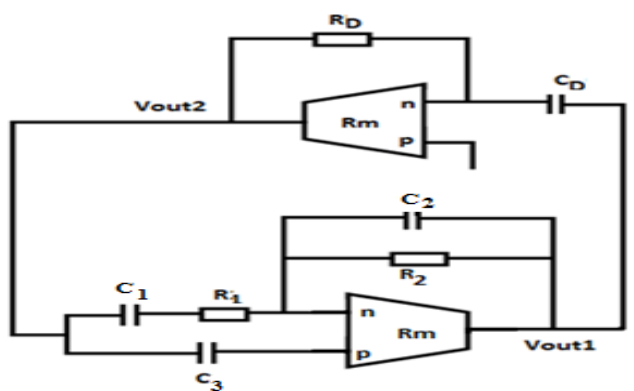

Figure 2. Proposed circuit

Assuming $\mathrm{C}_{2}=\mathrm{C}_{1}$ the condition of oscillation (CO) and frequency of oscillation (FO)

$$
\begin{aligned}
& \text { F.O: } f=\frac{\sqrt{R_{1}+R_{2}}}{2 \pi \sqrt{C_{3} R_{1} R_{2} R_{D} C_{D}}} \\
& \text { CO: }\left(R_{1}+R_{2}\right) C_{2}=R_{D} C_{D}
\end{aligned}
$$

The FO can be adjusted to desired value through $R_{1}, R_{2}$ and proper selection of resistor $R_{D}$ would satisfy the CO.

\section{NONIDEAL ANALYSIS}

Ideally the transresistance gain $R_{m}$ is assumed to approach infinity. However, practically $R_{m}$ is a frequency dependent finite value. The output of the QO may deviate due to non-ideality of OTRA in practice. Considering a single pole model for the trans-resistance gain, $\mathrm{R}_{\mathrm{m}}$ can be expressed as

$$
R_{m}(s)=\left(\frac{R_{o}}{1+\frac{s}{\omega_{o}}}\right)
$$

Where $R_{O}$ represents the dc transresistance gain. For high frequency applications the transresistance gain $R_{m}(s)$ reduces to

$$
R_{m}(s)=\frac{1}{s C_{P}}, \quad \text { where } C_{P}=\frac{1}{R_{O} \omega_{O}}
$$

Taking this effect into account the characteristic Equation given by (2) modifies to

$$
W s^{3}+X s^{2}+Y s+Z=0
$$

Where the coefficients $\mathrm{W}, \mathrm{X}, \mathrm{Y}$, and $\mathrm{Z}$ can be expressed as

$$
W=C C_{2} C_{P} R_{D}+C_{P}^{2} C R_{D}+C^{2} C_{D} R_{D}
$$




$$
X=C C_{2}+C C_{P}+C C_{P} \frac{R_{D}}{R_{2}}+C_{P} C_{2} \frac{R_{D}}{R_{1}}+C_{P}^{2} C \frac{R_{D}}{R_{1}} ; Y=\frac{C}{R_{2}}+\frac{\left(C_{2}+C_{P}\right)}{R_{1}}+\frac{R_{D} C_{P}}{R_{1} R_{2}} ; Z=\frac{1}{R_{1} R_{2}}
$$

Due to parasitic effect the FO and CO also change and are given by (8) and (9) respectively

$$
\begin{aligned}
& \text { FO: } f=\sqrt{\frac{\frac{R_{D} C_{P}}{R_{1}+R_{2}}+\frac{C}{R_{2}}+\frac{C_{2}+C_{P}}{R_{1}}}{C^{2} C_{D} R_{D}+C R_{D}\left(C_{2}+C_{P}\right)}} \\
& \mathrm{CO}:\left(C_{2}+C_{P}\right) R_{2}+C R_{1}+C_{P} R_{D}=\frac{R_{1} R_{2} R_{D}\left\{C\left(C_{2}+C_{P}\right)+C^{2} C_{D}\right\}}{R_{2}\left(C+C_{P}\right)\left(R_{1} C+R_{D} C_{P}\right)+R_{1} R_{D} C_{P} C}
\end{aligned}
$$

As the parasitic capacitance of the OTRA is very small, using approximation $\left(C_{2}+C_{P}\right) \approx C$ the $\mathrm{W}, \mathrm{X}, \mathrm{Y}$ and $\mathrm{Z}$ coefficients can be simplified as

$$
\begin{aligned}
& W=C C_{2} C_{P} R_{D}+C_{P}^{2} C R_{D}+C^{2} C_{D} R_{D} \\
& =C R_{D}\left(C_{P}\left(C_{2}+C_{P}\right)+C C_{D}\right) \\
& \approx C R_{D}\left(C_{P} C+C C_{D}\right) \approx C^{2} R_{D}\left(C_{P}+C_{D}\right) \approx C^{2} R_{D} C_{D} \\
& X=C C_{2}+C C_{P}+C C_{P} \frac{R_{D}}{R_{2}}+C_{P} C_{2} \frac{R_{D}}{R_{1}}+C_{P}^{2} C \frac{R_{D}}{R_{1}} \\
& =C\left(C_{2}+C_{P}\right)+C_{P}\left(C_{2}+C_{P}\right) \frac{R_{D}}{R_{1}}+\frac{R_{D}}{R_{2}} C_{P} C \approx C^{2}+C C_{P}\left(\frac{R_{D}}{R_{1}}+\frac{R_{D}}{R_{2}}\right) \\
& \approx C^{2} \text { as } C C_{P}<<C^{2} \\
& Y=\frac{C}{R_{2}}+\frac{\left(C_{2}+C_{P}\right)}{R_{1}}+\frac{R_{D} C_{P}}{R_{1} R_{2}} \approx Y=\frac{C}{R_{2}}+\frac{C}{R_{1}}+\frac{R_{D} C_{P}}{R_{1} R_{2}} \text { as } C_{P}<C< \\
& \approx \frac{C}{R_{2}}+\frac{C}{R_{1}} \quad \text { and } Z=\frac{1}{R_{1} R_{2}}
\end{aligned}
$$

By substituting W, X, Y, Z from (10), (11), (12) in (7) the characteristic Equation and hence the FO and $\mathrm{CO}$ can be obtained which are same as given by (2), (3) and (4) respectively.

\section{MOS-C IMPLEMENTATION}

The differential input of OTRA allows the resistors connected to the input terminals of OTRA to be implemented using MOS transistors with complete non-linearity cancellation [33]. Each resistor implementation require two matched N MOS transistorsas shown in Figure 3.

Figure 4 shows a typical MOS based implementation of resistance connected at inverting terminal of OTRA where nodes $\mathrm{X}$ and $\mathrm{Y}$ need to be connected to inverting and non-inverting terminals of the OTRA respectively. The value of resistance so obtained is expressed as

$$
R=\frac{1}{\mu_{n} C_{o x}(W / L)\left(V_{a}-V_{b}\right)}
$$

Where $\mu, \mathrm{C}_{\mathrm{OX}}$ and $\mathrm{W} / \mathrm{L}$ represent standard transistor parameters and $\mathrm{V}_{\mathrm{a}}$ and $\mathrm{V}_{\mathrm{b}}$ are the gate voltages. The MOS based implementation of the proposed circuit of Figure 2 is shown in Figure 4. The resistance value may be adjusted by appropriate choice of gate voltages thereby making oscillator parameters electronically tunable. 


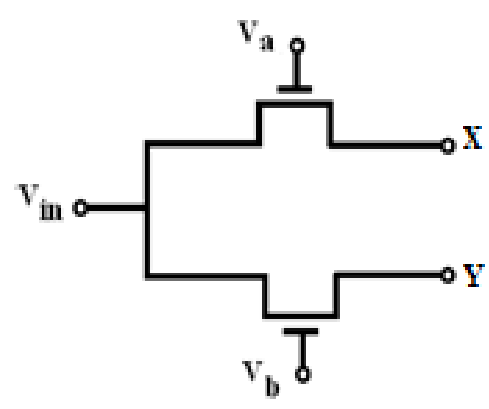

Figure 3. The MOS based resistor [33]

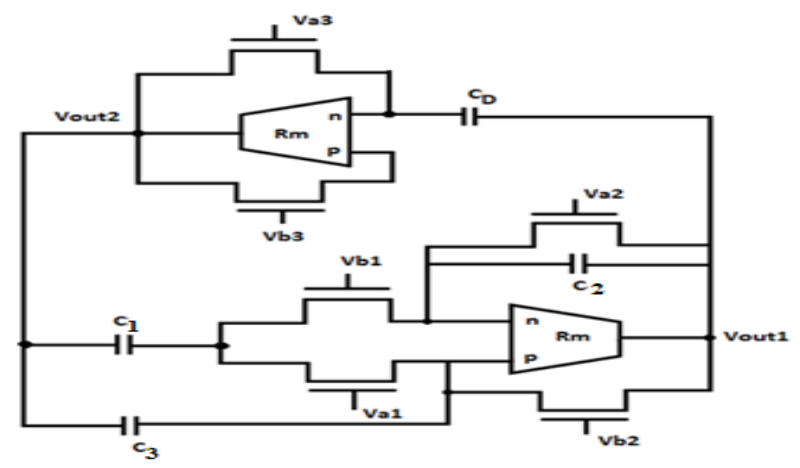

Figure 4. The MOS based implementation of QO Circuit

\section{PHASE NOISE ANALYSIS}

The random frequency fluctuations in a phase of a signal can be treated as a phase noise.To calculates the phase noise a procedure discussed in [35], [36] is adopted. The open loop transfer function $\mathrm{H}(\mathrm{s})$ of the oscillator circuit of Figure 2 is given by

$$
H(s)=\frac{-s^{3} C_{1} C_{3} C_{D} R_{D} R_{1} R_{2}}{\left(1+s C R_{1}\right)\left(1+s C R_{2}\right)}
$$

The H(s) given by (14) can also be expressed in terms of magnitude and phase as

$$
H(j \omega)=A(\omega) \cdot e^{j \phi \omega}
$$

From (15)

$$
\frac{d H}{d \omega}=\left(\frac{d A}{d \omega}+\mathrm{jA} \frac{d \phi}{d \omega}\right) e^{j \phi \omega}
$$

Substituting the $\mathrm{CO}$ and $\mathrm{FO}$ of the proposed oscillator in (14) the magnitude $\mathrm{A}(\omega)$ can be written as

$$
|A(\omega)|=\frac{\left(\frac{\omega}{\omega_{o}}\right)^{2} \omega}{\sqrt{\left(-\frac{1}{C_{D} R_{D}}\left(\frac{\omega}{\omega_{o}}\right)^{2}+\frac{1}{C\left(R_{1}+R_{2}\right)}\right)^{2}+\omega^{2}}}
$$

Determining $\left|\frac{d A}{d \omega}\right|$ from (16) results in $\left|\frac{d A}{d \omega}\right|=\frac{2}{\omega_{o}} \quad ; \angle H(\omega)=\phi=-\operatorname{Tan}^{-1}\left(\frac{\frac{1}{\omega C_{D} R_{D}}-\frac{1}{C \omega\left(\frac{\omega}{\omega_{o}}\right)^{2}\left(R_{1}+R_{2}\right)}}{\left(\frac{\omega}{\omega_{o}}\right)^{-2}}\right)$

Determining $\left|\frac{d \phi}{d \omega}\right|$ from (17) results in $\left|\frac{d \phi}{d \omega}\right|=\frac{2}{\omega_{o}^{2} C_{D} R_{D}}$

From Equation (18) it is clear that Frequency stability of proposed quadrature oscillator decreases with increase of $\omega_{o}$. 


\section{SENSITIVITY ANALYSIS}

The sensitivity is an important performance criterion of any network. The sensitivity of FO $\left(\omega_{o}\right)$ with respect to a circuit parameters, say $\mathrm{Y}$ is given as

$$
S_{Y}^{\omega_{o}}=\frac{\partial \omega_{o}}{\partial Y} \cdot \frac{Y}{\omega_{o}}
$$

Using this definition, the sensitivity of FO $\left(\omega_{o}\right)$ for the circuit w.r.t $\mathrm{R}_{1}, \mathrm{R}_{2}, \mathrm{C}$ are given as

$$
\left|S_{C_{D}}^{\omega_{o}}\right|=\left|S_{C}^{\omega_{o}}\right|=\frac{1}{2} ;\left|S_{R_{1}}^{\omega_{o}}\right|=\frac{R_{2}}{2\left(R_{1}+R_{2}\right)} ;\left|S_{R_{2}}^{\omega_{o}}\right|=\frac{R_{1}}{2\left(R_{1}+R_{2}\right)}
$$

From the above Equations it is observed that all passive sensitivities for both the circuits are lower than unity in magnitude. It ensures that the sensitivity performance is good.

\section{SIMULATION AND EXPERIMENTAL RESULT}

The proposed QO is verified through simulations using the CMOS implementation of the OTRA [9]. The SPICE simulations are performed using $0.18 \mu \mathrm{m}$ CMOS process parameters provided by MOSIS (AGILENT). Supply voltages taken are $\pm 1.5 \mathrm{~V}$. Component values are chosen as $\mathrm{C}_{1}=\mathrm{C}_{2}=\mathrm{C}_{3}=\mathrm{C}_{\mathrm{D}}=100 \mathrm{pF}$ and $\mathrm{R}_{1}=\mathrm{R}_{2}=5 \mathrm{~K} \Omega, \mathrm{R}_{\mathrm{D}}=10 \mathrm{~K} \Omega$ The simulated $\mathrm{FO}$ was observed to be $320 \mathrm{KHz}$ as against the calculated value of 318.47 KHz. The simulated transient output and corresponding frequency spectrum are shown in Figure 5(a) and 5(b) respectively.

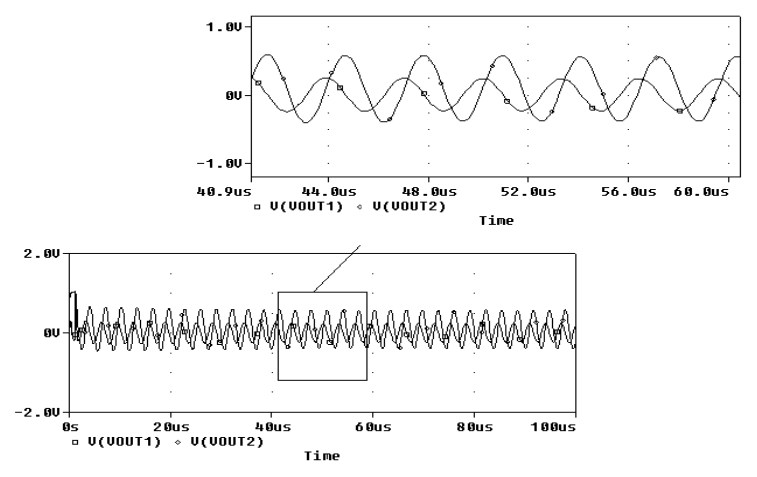

(a)

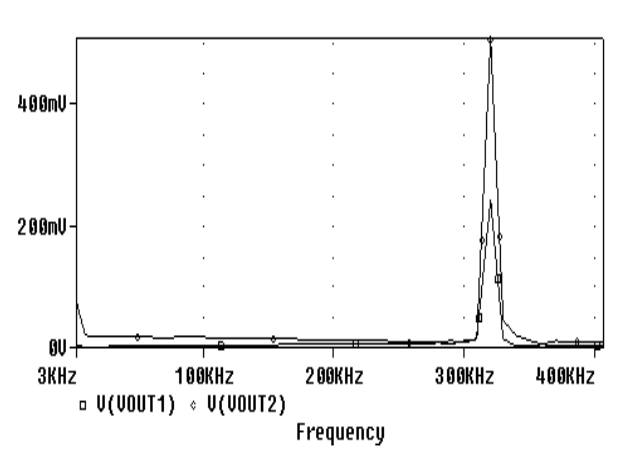

(b)

Figure 5. (a) Transient Output (b) Frequency spectrum of proposed QO circuit.

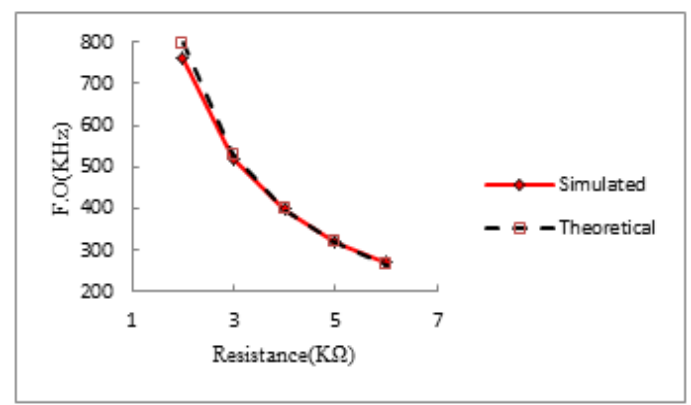

(a)

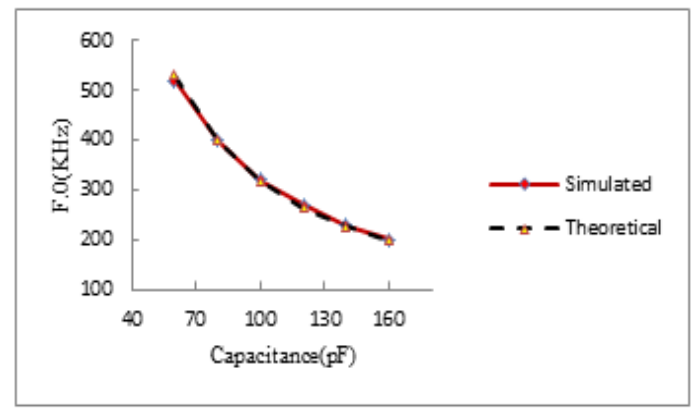

(b)

Figure.6. Frequency Tuning with (a) Resistance (b) with Capacitance for circuit 
The FO of the proposed QO can be tuned through $\mathrm{R}$ or $\mathrm{C}$ variations, as suggested by (3).The FO tuning with $\mathrm{R}$ (varied from $3 \mathrm{k} \Omega$ to $6 \mathrm{k} \Omega$ ) while keeping $\mathrm{C}$ fixed $(100 \mathrm{pF}$ ) is shown in Figure $6(\mathrm{a})$ whereas tuning with $\mathrm{C}$ (varied from $60 \mathrm{pF}$ to $140 \mathrm{pF}$ ) with $\mathrm{R}$ fixed at $5 \mathrm{k} \Omega$ is depicted in Figure $6(\mathrm{~b})$. It may be observed that the simulated and theoretical values of $\mathrm{FO}$ are in close agreement.

The \% THD variation with $\mathrm{R}$ and $\mathrm{C}$ is also studied and is depicted in Figure 7.The \% THD variation with $\mathrm{R}(\mathrm{C}=100 \mathrm{pF})$ for both Quadrature outputs, is recorded in Figure 7(a) and the largest value observed is $1.87 \%$. Similarly Figure 7(b) shows \% THD variation with $\mathrm{C}(\mathrm{R}=5 \mathrm{k} \Omega)$ where in the maximum observed value is well within $2.5 \%$. The phase error plots between $\mathrm{V}_{\text {out1 }}$ and $\mathrm{V}_{\text {out2 }}$ are drawn in Figure 8. Variation of phase error with resistance and capacitance are depicted in Fig.ure 8(a) and 8(b) respectively.

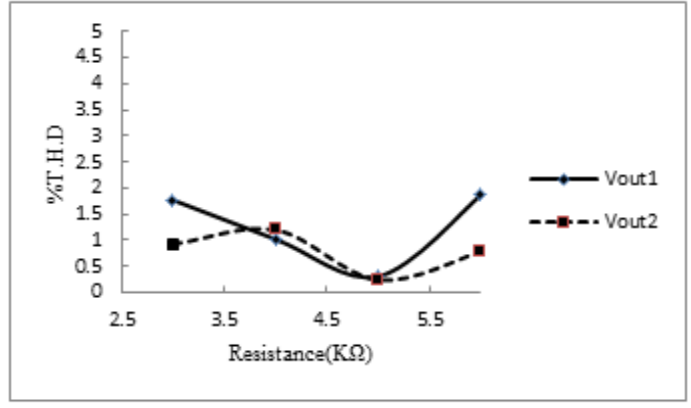

(a)

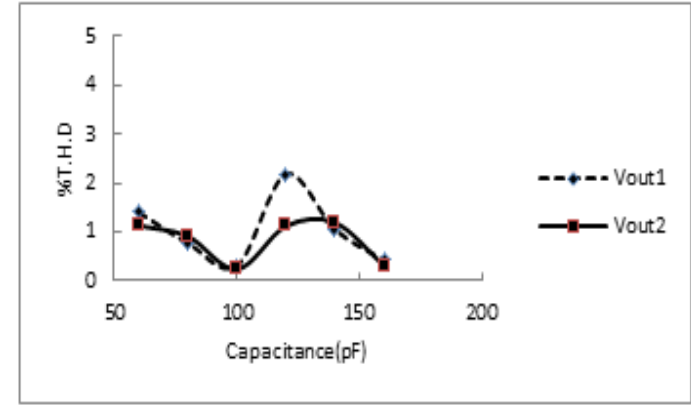

(b)

Figure 7. The \% THD variation with (a) Resistance (b) Capacitance for circuit

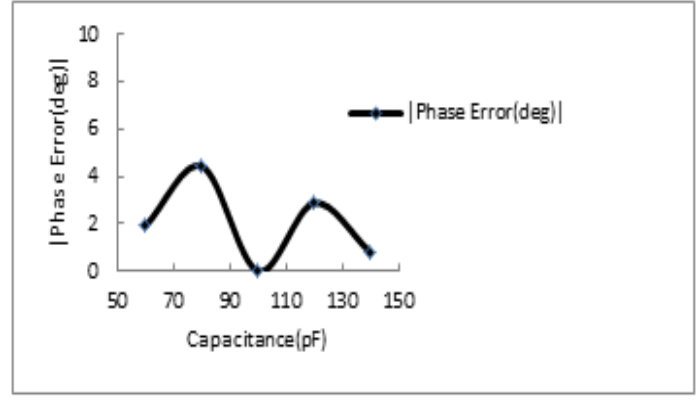

(a)

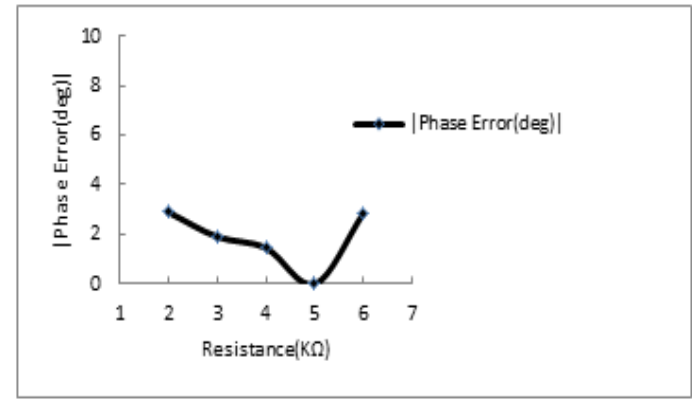

(b)

Figure 8. Phase error between Vout1 and Vout2 with (a) Capacitance (b) Resistance for circuit

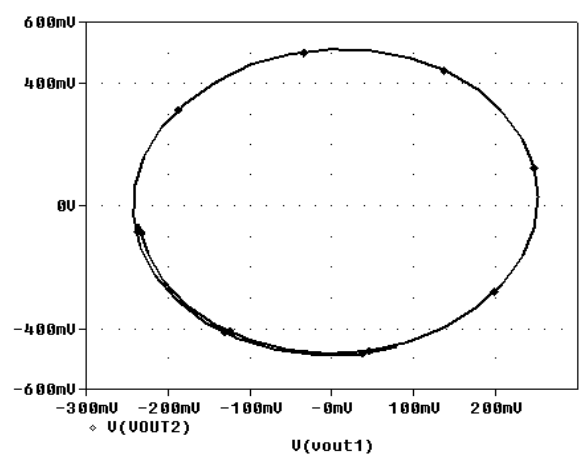

Figure.9. Plot of Vout1 vs Vout2

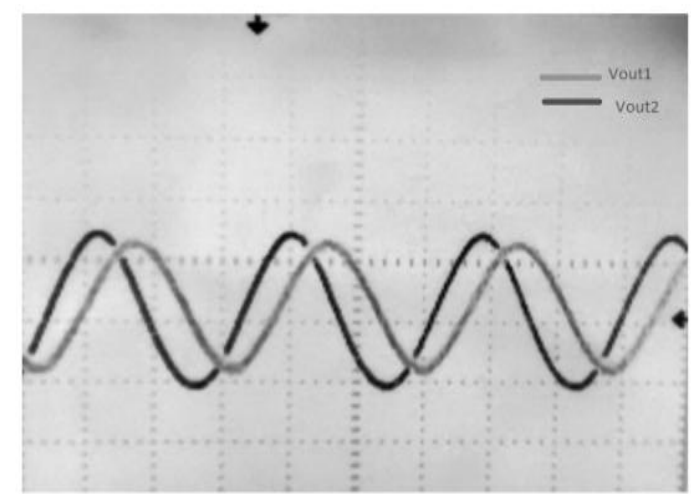

Figure.10. Transient Response of Proposed circuit on CRO 
The plot of Vout 1 vs Vout 2 is shown in Figure 9. The proposed quadrature oscillator is also tested experimentally by bread boarding the circuit of Figure 2 and the corresponding transient response shown in Figure 10.The OTRA is realized using Current feedback operational amplifier (CFOA) IC AD844AN [34] with power supply of $\pm 8 \mathrm{~V}$.

\section{CONCLUSION}

New realization of OTRA based third order quadrature oscillator is presented in this paper using a high pass filter and a differentiator. The functionality of proposed structure is verified through SPICE simulations using $0.18 \mu \mathrm{m}$ technology parameter. This topology is further tested experimentally where in the OTRA is realized using off the shelf CFOA IC AD844.The simulation and experimental results are found to be in close agreement with theoretical propositions. The simulated value of $\%$ THD is quite low. The phase noise analysis is also discussed for the proposed Q.O.The sensitivity of $\omega$ w.r.t passive components is also calculated and observed to be low.

\section{REFERENCES}

[1] D. Biolek, R. Senani, V. Biolkova, Z. Kolka, "Active Elements for Analog Signal Processing: Classification, Review and New Proposals," Radioengineering, vol. 7, pp. 15-32, 2008.

[2] K. N. Salama, A. M. Soliman, "CMOS Operational Transresistance Amplifier for analog Signal Processing Applications," Microelectron. J, vol. 30 , pp. 235-245, 1999.

[3] A. S. Sedra, K. C. Smith, Microelectronic Circuits ( Oxford University Press, New York, 2004)

[4] R. Holzel, "A Simple wide-band sine wave Quadrature Oscillator," IEEE Transactions on Instrumentation and Measurement, 42 (1993), pp. 758-760.

[5] M. T Ahmed, I. A. Khan, N. Minhaj, "On Transconductance-C Quadrature Oscillators," International Journal of Electronics, vol. 83, pp. 201-207, 1997.

[6] M. T. Abuelma'atti, H. A. Alzaher, "Comment on Current mode quadrature sinusoidal oscillator using single FTFN," International Journal of Electronics, vol. 85, pp. 177-180, 1988.

[7] C Cakir, U. Cam, O. Cicekoglu, "Novel all pass Filter Configuration Employing Single OTRA," IEEE Transactions on Circuits and Systems II: express briefs, vol. 52, pp. 22-125, 2005.

[8] S.S. Gupta, R. Senani, "Grounded Capacitor SRCOs using differential difference Complementary current feedback Amplifier," IEE Proc. Circuits Devices Syst ,vol. 152, pp. 38-48, 2005.

[9] H. Mostafa, A. M. Soliman, "A modified Realization of the OTRA," Frequenz 60 (2006) 70-76.

[10] W. Tangsrirat, S. Pisitchalermpong, "CDBA-based Quadrature Sinusoidal Oscillator," Frequenz, vol. 61, pp. 102-104, 2007.

[11] M. Kumngern, P. Lamun, "All pass Section-Based Mixed-Mode Quadrature Sinusoidal Oscillator, International Conference on Control System," Computing and Engineering, (Penang, Malaysia, 2013), pp.226-229.

[12] J. Bajer, J. Vavra, D. Biolek, "Voltage-Mode Quadrature Oscillator using VD-DIBA Active Elements," Asia Pacific Conference on Circuits and Systems (APCCAS) IEEE, (Ishigaki 2014), pp.197 - 200.

[13] M. Kumngern, A. Auttaput, K. Dejhan, “DDCCTA-based Quadrature Oscillator," Eleventh International Conference on ICT and Knowledge Engineering, (Bangkok, Thailand, 2013), pp. 1-4.

[14] H. P. Chen, M. Y. Hsieh, C. C. Lin, W. Y. Huang, "CFOA-based Quadrature Oscillator Employing Grounded Capacitors, Information Science,” Electronics and Electrical Engineering (ISEEE), vol. 1, pp. 470 - 473, 2014.

[15] J. W. Horng, C. L. Hou, C. M. Chang, W. Y .Chung, H. W. Tang, Y. H, "Wein Quadrature Oscillators using CCIIs," Int. J. Electron. Commun, vol. 92 , pp. 21-31, 2005.

[16] P. Promme, K. Dejhan, "An Integrable Electronic Controlled Sinusoidal Oscillator using CMOS Operational Transconductance Amplifier," Int. J. Electron, vol. 89, pp. 365-379, 2002.

[17] T. Hajder, "Higher Order Loops Improve Phase Noise of Feedback Oscillators," Applied Microwave and Wireless, vol. 14, pp. 24-30, 2002.

[18] J. W. Horng, "Current-Mode third-Order Quadrature Oscillator using CDTAs,"Active and Passive Electronic Components, vol. 2009 Article ID 789171, pp. 1-5, 2009.

[19] J. W. Horng, "Quadrature Oscillators using Operational Amplifiers,"Active and Passive Electronic Components, vol. 2011, Article ID 320367, pp. 1-4, 2011.

[20] J. W. Horng, "Current/ Voltage Mode third Order Quadrature Oscillator Employing two Multiple Outputs CCIIs and Grounded Capacitor," Indian J. Pure Appl. Phys ,vol. 49, pp. 494-988, 2011

[21] S. Maheshwari, I. A. Khan, "Current Controlled third Order Quadratureoscillator," IEE Proc., Circuits Devices Syst ,vol.152, pp. 605-7, 2005.

[22] S. Maheshwari, I. A. Khan, "Current Controlled third Order Quadrature Oscillator," IET Circuits Devices Systems, vol. 4, pp.188-95, 2010.

[23] S. Maheshwari, R. Verma, "Electronically Tunable Sinusoidal OscillatorCcircuit," Act. Passive Electron. Compon, vol. 2012, Article ID 719376, pp. 1-6, 2012.

[24] S. Maheshwari, “Analogue Signal Processing Applications using a new Circuit Topology,” IET Circuits Devices Syst, vol. 3 pp. 106-115, 2009. 
[25] J. W. Horng, H. Lee and J. Y Wu, "Electronically Tunable third-Order Quadrature Oscillator using CDTAs," Radioengineering, vol. 19 ,pp. 326-330, 2010.

[26] R. Pandey, N. Pandey and S. K. Paul, "MOS-C third Order Quadrature Oscillator using OTRA," Third International Conf. on Communication and Computer Technology, ICCCT, (Allahabad,India,2012), pp.77-80.

[27] S. Lawanwisut and M. Siripruchyanun, "High Output-Impedance Current-Mode third-Order Quadrature Oscillator based on CCCCTAs," TENCON 2009-2009 IEEE Region 10 Conf, (Singapore,2009), pp. 1-4.

[28] A. Kwawsibsam, B. Sreewirote, W. Jaikla, "Third-order Voltage-Mode Quadratrue Oscillator using DDCC and OTAs, ”Int. Conf. on Circuits, System and Simulation, vol. 7, (Singapore,2011), pp.317-321.

[29] M. Kumngern, S. Junnapiya, "Current-Mode third-Order Quadrature Oscillator using Minimum Elements," Int. Conf. on Electrical Engineering and Informatics, (Bandung, Indonesia, 2011), pp.1-4.

[30] D. Duangmalai, W. Jaikla, "Realization of Current-Mode Quadrature Oscillator based on third order Technique," ACEEE Int. J. Electr. Power Eng, vol. 2 , pp. 46-49,2011.

[31] N. Pandey, R. Pandey, "Approach for third Order Quadrature Oscillator Realisation," IET Circuits Devices Syst, vol. 9(3), pp. 161 - 171, May 2015

[32] B. Nagar, S. Paul, "Voltage Mode third Order Quadrature Oscillators using OTRAs," Analog Integrated Circuits and Signal Processing, vol. 88, no. 3, pp. 517-530, 2016.

[33] A. Gökçen, S. Kılınç, U. Çam, "Second Order Analog Filter Design Using a Single OTRA suitable for integration," Signal Processing and Communications Applications IEEE ,2007.

[34] M. Bothra, R. Pandey, N. Pandey, S. K. Paul, "Operational TransResistance Amplifier Based Tunable Wave Active Filter," Radioengineering, vol. 22 , pp. 159-166,2013.

[35] B. Razavi, "Analysis, Modeling and Simulation of Phase Noise in Monolithic Voltage Controlled Oscillators," IEEE Custom Integrated Circuits Conference, pp. 323-326. 1995.

[36] B. Razavi, "A Study of Phase noise in CMOS Oscillators,"IEEE Journal of Solid State Circuits, vol. 31,no.3 pp.2014-2021. 1996.

[37] M.Hamiane, "A CMOS-based Analog Function Generator: HSPICE Modeling and Simulation,"International Journal of Electrical and Computer Engineering (IJECE),vol. 4, no. 4, pp. 532-538, August 2014.

[38] P. Nugroho, Ramesh K. Pokharel, H.Kanayaand K.Yoshida "A 5.9 GHz Low Power and Wide Tuning Range CMOS Current-controlled Ring Oscillator," International Journal of Electrical and Computer Engineering (IJECE), vol 2, No 3,June 2012.

\section{BIOGRAPHIES OF AUTHORS}

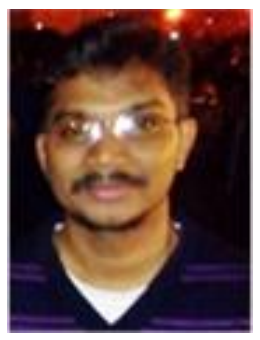

Gurumurthy Komanapalli received his B.Tech. (Electronics and Communication) from Avanthi Institute of Engineering \& Tech,JNTU Kakinada, Andhrapradesh and his MTECH in VLSI design from Delhi Technological University((formerly Delhi College of Engineering), New Delhi in 2014 and Currently he is pursuing his Doctorate from Delhi Technological University. His research interests are in analog circuit design and microelectronics.

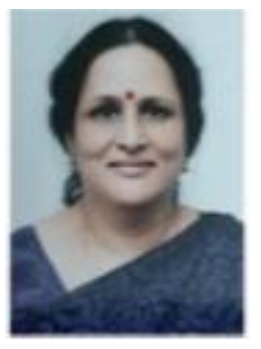

Neeta Pandey received her M.E. in Microelectronics from Birla Institute of Technology and Sciences, Pilani andPh.D. from Guru Gobind Singh Indraprastha University, Delhi. She has served in Central Electronics Engineering Research Institute, Pilani, Indian Institute of Technology, Delhi, Priyadarshini College of Computer Science, Noida and Bharati Vidyapeeth's College of Engineering, Delhi in various capacities. At present, she is assistant professor in ECE department, Delhi Technological University. A life member of ISTE, and member of IEEE, USA, she has published papers in international, national journals of repute and conferences. Her research interests are in analog and digital VLSI design.

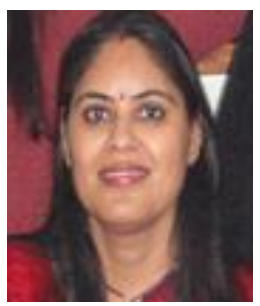

Rajeshwari Pandey received her B.Tech. (Electronics and Telecommunication) from J. K. Institute of Applied Physics, University of Allahabad in 1988 and her M. E. (Electronics and Control) from BITS, Pilani, Rajasthan, India in 1992. She has served BITS Pilani, AERF, Noida and Priyadarshini College of Computer Science, Noida in various capacities. Currently, she is assistant professor in Department of Electronics \& Communication Engineering, Delhi Technological University, Delhi. Her research interests include analog integrated circuits and microelectronics. 